\title{
Combination and tricombination therapy to destabilize the structural integrity of COVID-19 by some bioactive compounds with antiviral drugs: insights from molecular docking study
}

\author{
H. R. Abd El-Mageed ${ }^{1}$ • Doaa A. Abdelrheem ${ }^{2}$ - Shimaa A. Ahmed ${ }^{2}$ - Aziz A. Rahman ${ }^{3}$ - Khaled N. M. Elsayed ${ }^{4}$. \\ Sayed A. Ahmed ${ }^{2}$ - Ashraf A. EL-Bassuony ${ }^{2} \cdot$ Hussein S. Mohamed ${ }^{5}$
}

Received: 30 June 2020 / Accepted: 29 December 2020 / Published online: 8 January 2021

(C) Springer Science+Business Media, LLC, part of Springer Nature 2021

\begin{abstract}
Recently, the SARS-CoV-2 (COVID-19) pandemic virus has been spreading throughout the world. Until now, no certified drugs have been discovered to efficiently inhibit the virus. The scientists are struggling to find new safe bioactive inhibitors of this deadly virus. In this study, we aim to find antagonists that may inhibit the activity of the three major viral targets: SARS-CoV-2 3chymotrypsin-like protease (6LU7), SARS-CoV-2 spike protein (6VYB), and a host target human angiotensin-converting enzyme 2 (ACE2) receptor (1R42), which is the entry point for the viral encounter, were studied with the prospects of identifying significant drug candidate(s) against COVID-19 infection. Then, the protein stability produced score of less than 0.6 for all residues of all studied receptors. This confirmed that these receptors are extremely stable proteins, so it is very difficult to unstable the stability of these proteins through utilizing individual drugs. Hence, we studied the combination and tricombination therapy between bioactive compounds which have the best binding affinity and some antiviral drugs like chloroquine, hydroxychloroquine, azithromycin, simeprevir, baloxavir, lopinavir, and favipiravir to show the effect of combination and tricombination therapy to disrupt the stability of the three major viral targets that are mentioned previously. Also, ADMET study suggested that most of all studied bioactive compounds are safe and nontoxic compounds. All results confirmed that caulerpin can be utilized as a combination and tricombination therapy along with the studied antiviral drugs for disrupting the stability of the three major viral receptors (6LU7, 6VYB, and 1R42).
\end{abstract}

Keywords COVID-19 virus protease $\cdot$ Natural products $\cdot$ Caulerpin $\cdot$ Molecular docking $\cdot$ MLSD

Sayed A. Ahmed

Sayed.hassan@science.bsu.edu.eg

1 Micro-analysis and Environmental Research and Community Services Center, Faculty of Science, Beni-Suef University, Beni-Suef City, Egypt

2 Department of Chemistry, Faculty of Science, Beni-Suef University, Beni-Suef 62511, Egypt

3 Department of Pharmacy, University of Rajshahi, Rajshahi, Bangladesh

4 Department of Botany, Faculty of Science, Beni-Suef University, Beni-Suef, Egypt

5 Research Institute of Medicinal and Aromatic Plants (RIMAP), Beni-Suef University, Beni-Suef City, Egypt

\section{Introduction}

Coronaviruses $(\mathrm{CoV})$ are a great family of viruses that cause illness ranging from the common cold to more severe diseases like Middle East respiratory syndrome (MERS), and severe acute respiratory syndrome (SARS). Also, their structure has a characteristic RNA genome. However, coronaviruses are more common with animals; seven of them can stimulate the human respiratory system [1]. From December 2019, a new coronavirus called COVID-19 that firstly occurred in Wuhan, Hubei Province of China, is now spreading speedily through China and other parts of the world. COVID-19 has become a critical threat to the world public health, causing 245,792 deaths from $3,484,640$ cases as of 3 May 2020 from the entire world. The current COVID-19 
outbreak is caused by SARS-CoV-2 that has been known as the seventh member of the family of coronaviruses [1]. SARSCoV-2 3-chymotrypsin-like protease (3CLpro) was established to have higher sequence homology toward SARS-CoV than that of MERS-CoV according to the whole genome sequence alignment analysis in different studies [2]. The difference between SARS-CoV-2 and SARS-CoV is characterized as a complement of 3 'ORF, namely ORF $3 \mathrm{~b}$ and ORF 10 along with intact ORF 8 in SARS-CoV-2, while SARS-CoV encodes for ORF 8a/b [3]. Four structural proteins which characterize coronavirus genome (spike glycoprotein $(\mathrm{S})$, nucleocapsid protein $(\mathrm{N})$, matrix glycoprotein $(\mathrm{M})$, and small envelope protein (E)) were reported [4]. Furthermore, 3CLpro is also known as Nsp5 of SARS-Cov2 needed for the maturation of coronaviruses, demonstrating that 3CLpro is critical for the virus life cycle. So, 3CLpro is an inviting target for an evolving drug against coronavirus [5]. SARS-CoV-2 spike protein simplifies the entrance of viral particles into the host cell after binding with the host angiotensin-converting enzyme 2 (ACE2) and the spike protein also defined the host range [6]. The utilization of natural compound alternatives or complementary therapies has received growing attention due to their low toxicity and fewer side effects. Chemical drugs have shown different side effects and ineffectiveness in some cases for long-term use. The World Health Organization (WHO) evaluated that about $80 \%$ of people use natural compounds in the treatment field of different diseases [7]. Essentially, natural compounds have various and effective biological activities such as antimicrobial, anticancer, anti-inflammatory, and anti-diabetic [8-26]. In this work, we study the inhibitory effect of some bioactive compounds obtained from natural sources against SARSCoV-2-3CLpro (6LU7), SARS-CoV-2 spike protein (6VYB), and a host target human angiotensin-converting enzyme 2 (ACE2) receptor (1R42) by molecular docking analysis, where we can identify the favorable molecules from all studied compounds for COVID-19 treatment and compare them to proposed drugs like chloroquine, azithromycin, simeprevir, baloxavir, hydroxychloroquine, favipiravir, and lopinavir. Then, we studied the combination and tricombination therapy between bioactive compounds which have the best binding affinity and the studied antiviral drugs to show the effect of combination and tricombination therapy to disrupt the stability of $6 \mathrm{LU} 7,6 \mathrm{VYB}$, and $1 \mathrm{R} 42$ receptors. Finally, the pharmacogenetic and toxicity properties of all studied compounds also are computed.

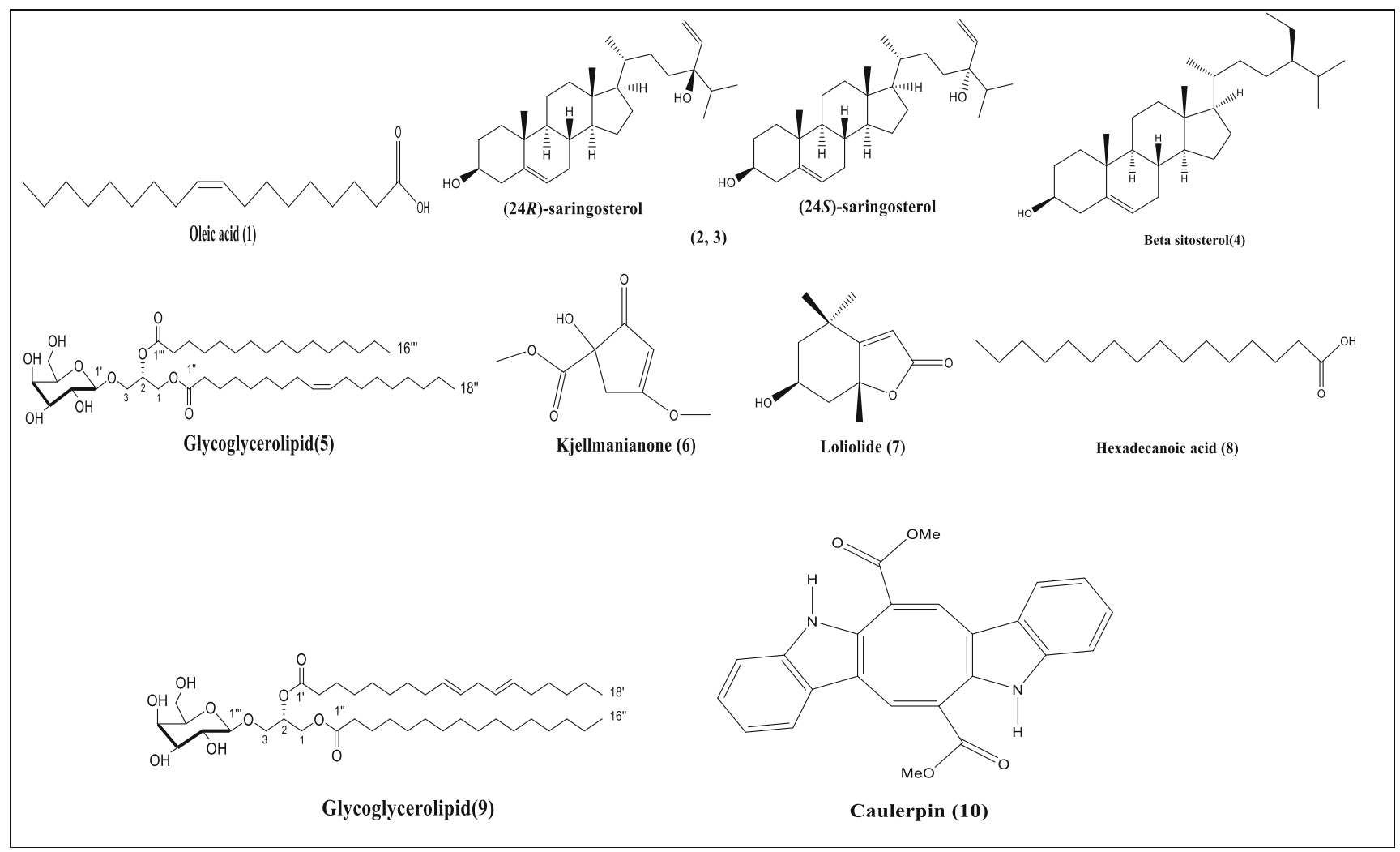

Fig. 1 All studied bioactive compounds in this work 


\section{Materials and methods}

\section{Structures and biological activity of all studied bioactive compounds}

In our study, we choose ten public bioactive compounds that already are abundant and isolated from different species of plants or marine algae to study their inhibitory effect against 6LU7, 6VYB, and 1R42 receptors. According to literature survey, these compounds showed a broad spectrum of biological activities like antimicrobial, antioxidant, anticancer, antiviral, and anti-inflammatory, making them an attractive target to evaluate their potential to become potential candidate inhibitors against SARS-CoV-2 receptors. All studied bioactive compounds in this work are summarized in Fig. 1. Also, their sources, species names, and biological activities are illustrated in Table 1 and Table S1 (S: Supporting Information).

\section{Protein and ligand preparation}

The crystal structures of SARS-CoV-2 main protease (PDB ID: 6LU7.pdb), spike protein (PDB ID: 6VYB.pdb), and human entry receptor ACE2 (PDB ID: 1R42.pdb) were retrieved from RCSB PDB that were downloaded from the Protein Data Bank (www.pdb.org). Any heteroatoms and water molecules were removed before the molecular docking study was performed. The 3-dimensional (3D) structures of all studied compounds and some proposed antiviral drugs (bioactive compounds, chloroquine, hydroxychloroquine, azithromycin, simeprevir, baloxavir, lopinavir, and favipiravir) were downloaded from PubChem (https://pubchem.ncbi.nlm.nih.

Table 1 The natural sources and biological activities of all studied compounds

\begin{tabular}{|c|c|c|c|}
\hline Compounds & Sources & Species name & Biological activity \\
\hline Oleic acid (1) & $\begin{array}{l}\text { Terrestrial plant } \\
\text { Red macroalgae } \\
\text { Green macroalgae } \\
\text { Brown macroalgae } \\
\text { Microalgae } \\
\text { Endophytic fungi form plant } \\
\text { Vegetable oils }\end{array}$ & $\begin{array}{l}\text { Zaleya decandra }{ }^{[8]} \\
\text { Ceramium virgatum } \\
\text { Ulva intestinalis }^{[9]} \\
\text { Fucus sp. }^{[10]} \\
\text { Chlorella vulgaris } \\
\text { Torreya grandis }{ }^{[12]} \\
\text { Hazelnut }^{[13]}\end{array}$ & $\begin{array}{l}\text { Antimicrobial, }{ }^{[13]} \text { anticancer, }{ }^{[14]} \text { and } \\
\text { antiviral activities }\end{array}$ \\
\hline Saringosterols $(2,3)$ & $\begin{array}{l}\text { Terrestrial plant } \\
\text { Red macroalgae } \\
\text { Green macroalgae } \\
\text { Brown macroalgae }\end{array}$ & 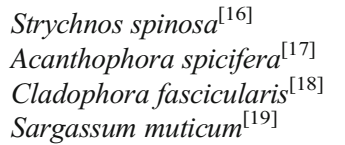 & $\begin{array}{l}\text { Antitrypanosomal, } \\
\text { novel selective } \operatorname{LXR} \beta \text { agonist }{ }^{[20]}\end{array}$ \\
\hline$\beta$-Sitosterol (4) & $\begin{array}{l}\text { Terrestrial plant } \\
\text { Red macroalgae } \\
\text { Green macroalgae } \\
\text { Brown macroalgae } \\
\text { Microalgae }\end{array}$ & $\begin{array}{l}\text { Synadenium glaucescens } \\
\text { Eucheuma cottonii }^{[22]} \\
\text { Ulva fasciata }^{[23]} \\
\text { Sargassum } \text { glaucescens }^{[24]} \\
\text { Nannochloropsis }^{[25]}\end{array}$ & $\begin{array}{l}\text { Antimicrobial, }{ }^{[26]} \text { antiviral activity against } \\
\text { hepatitis B virus, }{ }^{[27]} \\
\text { antioxidant and anticancer activities }{ }^{[28]}\end{array}$ \\
\hline Glycoglycerolipids $(5,9)$ & $\begin{array}{l}\text { Terrestrial plant } \\
\text { Red macroalgae } \\
\text { Brown macroalgae } \\
\text { Cyanobacteria }\end{array}$ & $\begin{array}{l}\text { Soybean }{ }^{[29]} \\
\text { Exophyllum wentii } i^{[30]} \\
\text { Sargassum horneri } i^{[31]} \\
\text { Phormidium } \text { sp. }^{[3]}\end{array}$ & $\begin{array}{l}\text { Accumulation inhibition, }{ }^{[29]} \text { antitumor, } \\
\text { antiviral, and anti-inflammatory activities }{ }^{[32]}\end{array}$ \\
\hline Kjellmanianone (6) & Brown macroalgae & Sargassum naozhouense ${ }^{[33]}$ & $\begin{array}{l}\text { Antibacterial effect against } E \text {. coli and } \\
\text { Bacillus subtilis }{ }^{[34]}\end{array}$ \\
\hline Loliolide (7) & $\begin{array}{l}\text { Terrestrial plant } \\
\text { Brown macroalgae }\end{array}$ & $\begin{array}{l}\text { Canscora decussata } \\
\text { Sargassum naozhouense }\end{array}$ & $\begin{array}{l}\text { Antioxidant and a cell protective effect on a } \\
\text { monkey kidney fibroblast cell line }{ }^{[36]} \text { and } \\
\text { anticancer, antibacterial, and antifungal activities }\end{array}$ \\
\hline Hexadecanoic acid (8) & Terrestrial plant & Canthium parviflorum $^{[38]}$ & $\begin{array}{l}\text { Antimicrobial, anti-inflammatory, antioxidant, } \\
\text { hypocholesterolemia, pesticide, hemolytic and } \\
\text { 5-alpha reductase inhibitor }{ }^{[40]} \text { and antiviral activity }\end{array}$ \\
\hline Caulerpin (10) & $\begin{array}{l}\text { Green macroalgae } \\
\text { Red macroalgae }\end{array}$ & 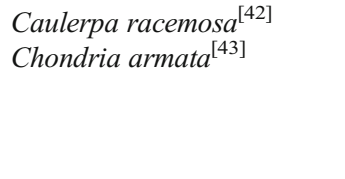 & $\begin{array}{l}\text { Antitumor, anti-diabetic, anticancer, anti-larvicidal, } \\
\text { anticorrosion, anti-herpes, antitubercular, } \\
\text { antimicrobial, cytotoxic, antiviral, spasmolytic, } \\
\text { antinociceptive, plant growth regulatory activity, } \\
\text { and anti-inflammatory activities }{ }^{44]}\end{array}$ \\
\hline
\end{tabular}


gov/), in .sdf format. PubChem is a chemical substance and biological activity repository consisting of three databases, including substance, compound, and bioassay databases. Determination of the amino acids in the active site of a protein was determined using the Biovia Discovery Studio to analyze the grid box and docking evaluation results.

\section{Molecular docking}

All ligands in this study (bioactive compounds, chloroquine, hydroxychloroquine, azithromycin, remdesivir, baloxavir, lopinavir, and favipiravir) were optimized before docking by Avogadro version 1.2, with Force Field type MMFF94, and saved in .pdb format. Discovery Studio was utilized for protein optimization, by removing water and other atoms to prepare protein for docking analysis. Molecular docking between ligands with 6LU7, 6VYB, and $1 \mathrm{R} 42$ receptors was performed utilizing auto dock tools (ADT) graphical user interface supported by MGL tools. Then, polar hydrogen was added and atomic charges were processed by the Kollman and Gasteiger method. A grid size used in
Fig. 2 Prediction of protein disorder using the IUPred web server for (5a) SARS-CoV-2 main protease (PDB ID: 6LU7), (5b) SARS-CoV-2 spike protein domain (PDB ID: 6VYB), and (5c) human entry receptor ACE2 (PDB ID: 1R42) receptors

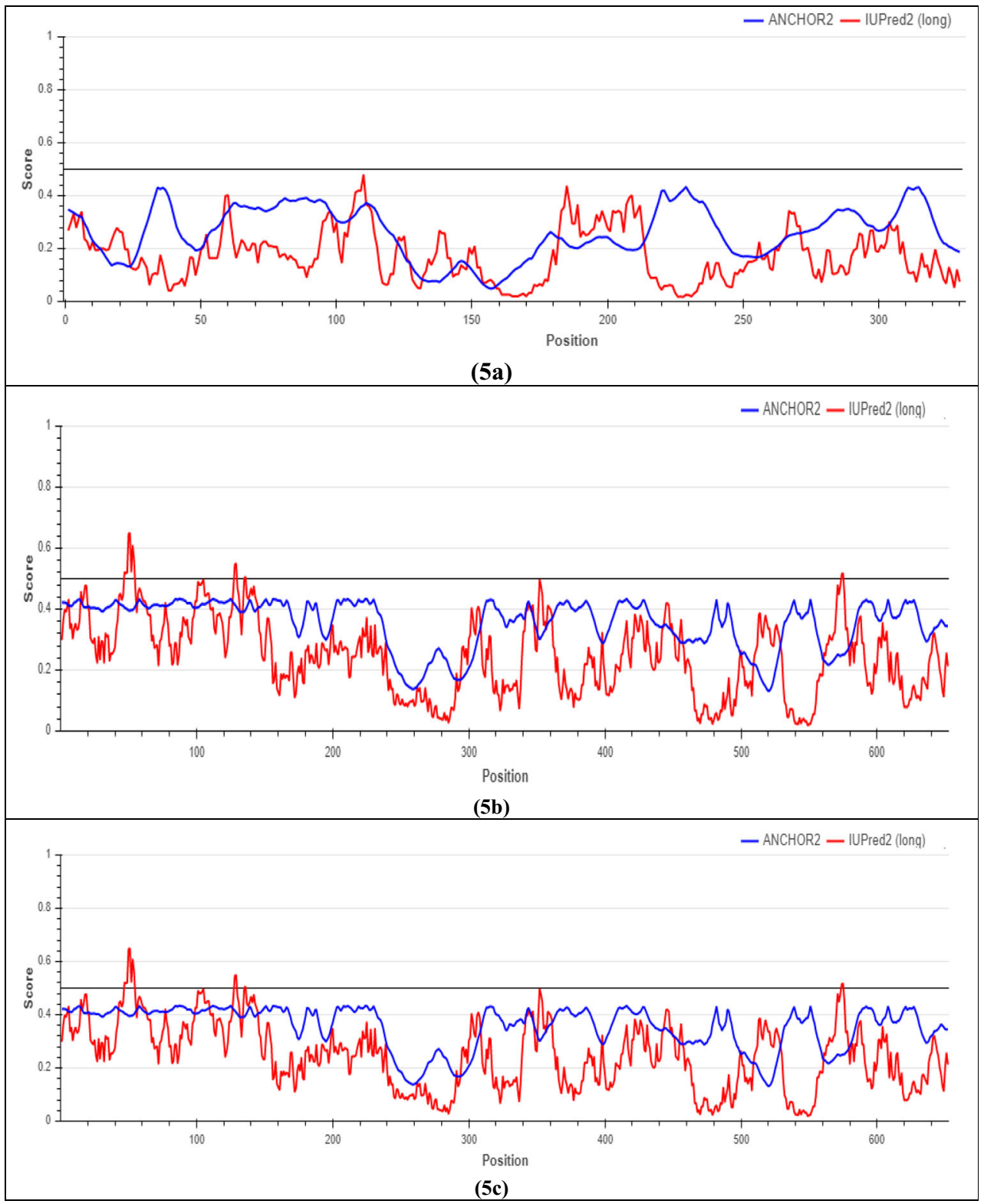


docking was specified with $70 \AA \times 70 \AA \times 70 \AA$ for the three receptors on the macromolecule binding pocket with a spacing of $0.365 \AA$ and the Lamarckian Genetic Algorithm (LGA) was assigned to do the molecular docking analysis, as indicated in this study [27]. Docking parameters were set as follows: the number of Lamarckian job $=40$, initial population $=150$, the maximum number of energy evaluation $=2.5 \times 10^{5}$; other parameters were set in their default value. Also, the grid was centered on all the receptors and ligands were kept flexible. All docking results were sorted from the lowest to highest of the docking score. Discovery studio program and PyMOL version 1.7.4.5 software package were used for further evaluation of the output of the docking study.

\section{Multiple ligand simultaneous docking}

We can estimate the interaction of multiple or different ligands inside the receptor via the multiple ligand simultaneous docking (MLSD) method. The present MLSD method simulates the AutoDock4 algorithms and scoring function to examine the interaction of multiple ligands inside the target receptor. MLSD dock parameters were placed as follows: ligand molecules were scanned separately by auto dock tools (ADT) and saved with suitable torsions and charges as .PDBQT files and the target molecule was also read and dock parameter file was produced as dpf file. With individual dock parameter files of the ligand molecules, substrate's dpf was combined into one single file to run MLSD simulation. Once prepared with the merged dock parameter file, docking begins with the random initialization of the population. MLSD stands separate from single ligand docking where different conformations of multiple ligands can be run simultaneously. For energy minimization, we used standard LGA and the pseudo-Solis and Wets methods. All applied MLSD method in this study and also the validation of docking analysis were done as described in this study [28].

\section{Validation of docking procedure}

The ligand's probable binding pattern was obtained based on their position and orientations identified after the molecular docking simulations. The parameters included in the current in silico study were validated by performing docking of the 6LU7 against the crystallized ligand N3. The crystallized conformation of the ligand N3 complexed within the active site of the viral 6LU7 is its bioactive conformation. The in silico docking methodology was validated through analyzing the subsequent parameters.
Analysis of drug likeness and ADMET properties of all studied bioactive compounds

The prediction of the drug likeness for all studied compounds in this study was performed by using the Lipinski website (http://www.scfbio-iitd.res.in/software/drugdesign/lipinski. jsp), agreeing to which an orally active drug should comply with a minimum of four of the five laid down criteria for drug likeness, namely molecular mass, cLogP, hydrogen donor and acceptor, and molar refractive index [29]. Furthermore, the pharmacokinetic properties such as absorption, distribution, metabolism, and excretion and the toxicity of all studied compounds were forecasted using the admetSAR website (http:// lmmd.ecust.edu.cn/admetsar1/predict) [30].

\section{Determination of protein stability}

The stability of protein receptors was decided using the webserver (http://iupred.enzim.hu and http://iupred.elte.hu) algorithm. IUPred2 and ANCHOR were assigned for this step. The FASTA file of protein receptors SARS-CoV-2 main protease (PDB ID: 6LU7) containing 306 residues, SARSCoV-2 spike protein domain (PDB ID: 6VYB) with 975

Table 2 Molecular docking analysis of studied compounds (1-10) and some antiviral drugs against 6LU7, 6VYB, and 1R42 receptors

\begin{tabular}{llll}
\hline Ligand & \multicolumn{3}{l}{ Binding energy $(\Delta G), \mathrm{kcal} / \mathrm{mol}$} \\
\cline { 2 - 4 } & $6 \mathrm{LU} 7$ & $6 \mathrm{VYB}$ & $1 \mathrm{R} 42$ \\
\hline 1 & -7.24 & -7.24 & -8.14 \\
2 & -7.47 & -7.37 & -7.33 \\
3 & -7.55 & -7.44 & -7.36 \\
4 & -8.02 & -7.65 & -8.40 \\
5 & -8.03 & -7.64 & -6.60 \\
6 & -9.22 & -8.09 & -8.16 \\
7 & -9.02 & -8.14 & -8.28 \\
8 & -8.10 & -9.70 & -8.40 \\
9 & -9.26 & -9.72 & -8.88 \\
10 & -9.30 & -9.77 & -9.97 \\
Chloroquine & -8.95 & -9.32 & -9.17 \\
Hydroxychloroquine & -9.23 & -9.38 & -9.27 \\
Azithromycin & -8.55 & -9.42 & -9.48 \\
Simeprevir & -9.24 & -9.67 & -9.45 \\
Baloxavir & -9.18 & -9.51 & -9.35 \\
Lopinavir & -9.28 & -9.56 & -9.59 \\
Favipiravir & -9.23 & -9.73 & -9.26 \\
\hline
\end{tabular}


residues, and human entry receptor ACE2 (PDB ID: 1R42) containing 640 residues was uploaded on webserver for protein disorder estimation $[3,31,32]$. The predication mechanism of IUPred algorithm depends on the energy estimation approach at a low-resolution statistical potential to discover the ability of amino acid pairs to produce contacts and examined as globular protein structures [33]. The statistical potential computes the energy for all residues related to its interactions with other structures contacting residues in the state of known structure. The total stabilizing energy of the system can be calculated by the sum of residue-level energy and intrachain interactions in protein structure energy. Consequently, this novel technique has been established to decide these energies exactly from the amino acid sequence of an unknown structure as shown in this study [34]. Similar to
IUPred, ANCHOR also utilizes the energy calculation method for identifying the disordered binding sites. In spite of the general disorder tendency, two additional terms have also been inserted into this method, to calculate the energy based on the interaction with a globular protein and with the disturbing sequence [35].

\section{Results and discussions}

\section{Prediction of protein stability}

The diagram is taken from the webserver https://iupred2a.elte. hu (Fig. 2) after the downloaded FASTA file of each protein receptors produced a score of less than 0.6 for all residues of
Fig. 3 2D interaction of studied compounds (1-6) inside 6LU7

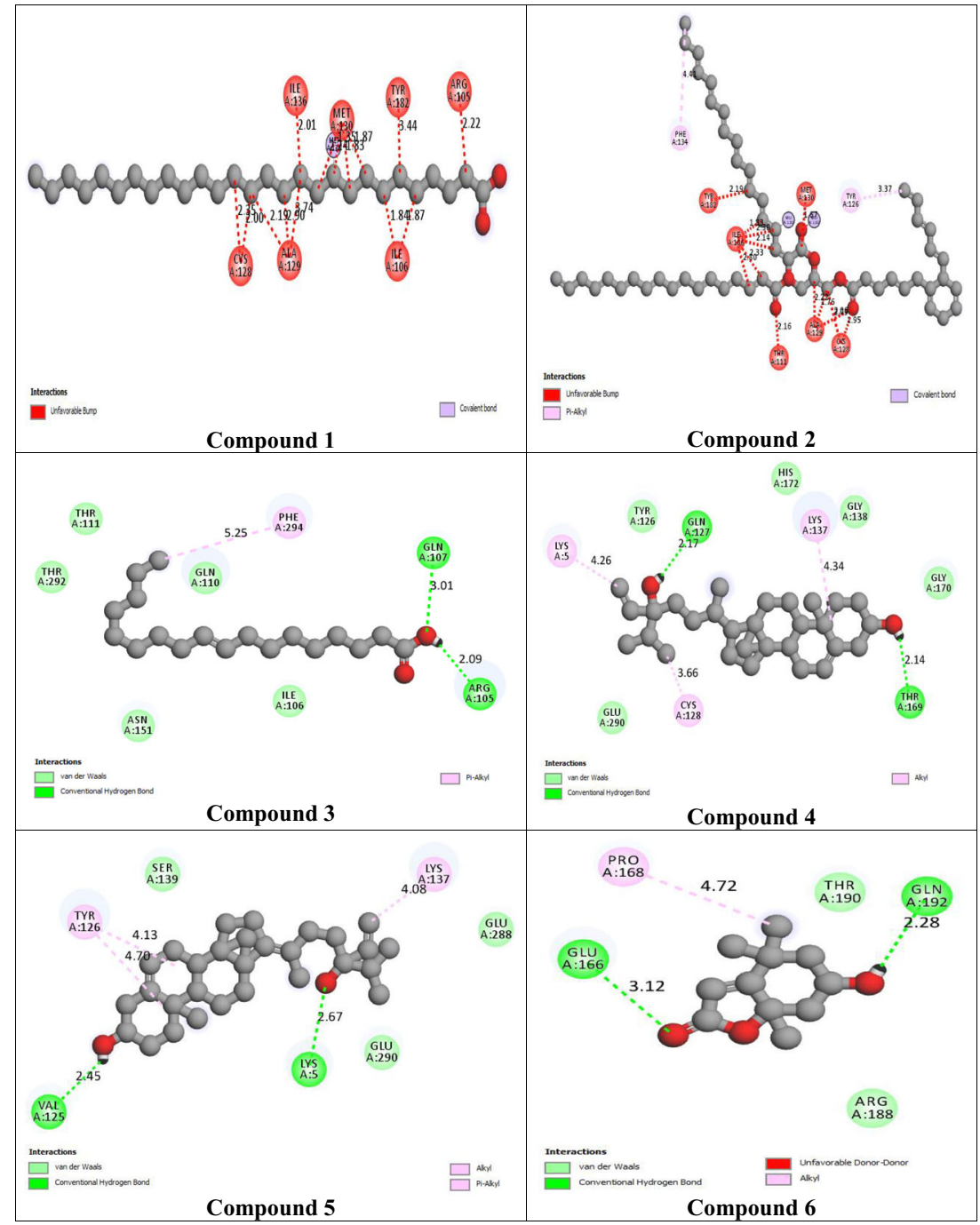


6LU7 as shown in figure (5a), 6VYB as shown in figure (5b), and 1R42 as shown in figure (5c) that show the reliability of residues in selected protein receptors of SARS-CoV2 is very high $[40,41]$. So, SARS-CoV-2 main protease, SARS-CoV-2 spike protein, and human entry receptor ACE2 are extremely stable proteins, so it is very difficult to unstable the stability of these proteins through using individual drugs. Hence, individual drug like lopinavir, simeprevir, hydroxychloroquine, chloroquine, and amprenavir may not be able to disrupt the stability of SARS-CoV-2 main protease (PDB ID: 6LU7), SARSCoV-2 spike protein domain (PDB ID: 6VYB), and human entry receptor ACE2 (PDB ID: 1R42).

\section{Validation of docking methodology}

The docking validation was carried out using our previously published work [36] with re-docking of the co-crystal structure (N3) as an inhibitor in the 6LU7 with the abovementioned parameters and values in the "Materials and methods" section. Firstly, N3 coordinates in the crystal complex of 6LU7 were removed and the bond orders were checked. Then, we performed the docking studies of N3 inside 6LU7 to validate the docking protocol. Once the docking is done, select the best pose based on binding energy, ligandreceptor interactions, and the active site residues. Then, simply align both docked pose with that of co-crystallized structure, and then, RMSD was calculated lower than $1.0 \AA$. Also, 2D interaction of $\mathrm{N} 3$ inhibitor inside 6LU7 is summarized in Figure S1. As shown in Figure S1, we found that N3 inhibitor interacts with GLN 189, THR 190, GLU 166, PHE 140, HIS 164, and GLY 143 amino acid residues of 6LU7 through hydrogen bond interactions and with PRO 168, MET 165, ALA 191, HIS 41, and MET 49 through alkyl and pi-alkyl interactions which are in good agreement of those in the state

Fig. 4 2D interaction of studied compounds (7-10) inside 6LU7

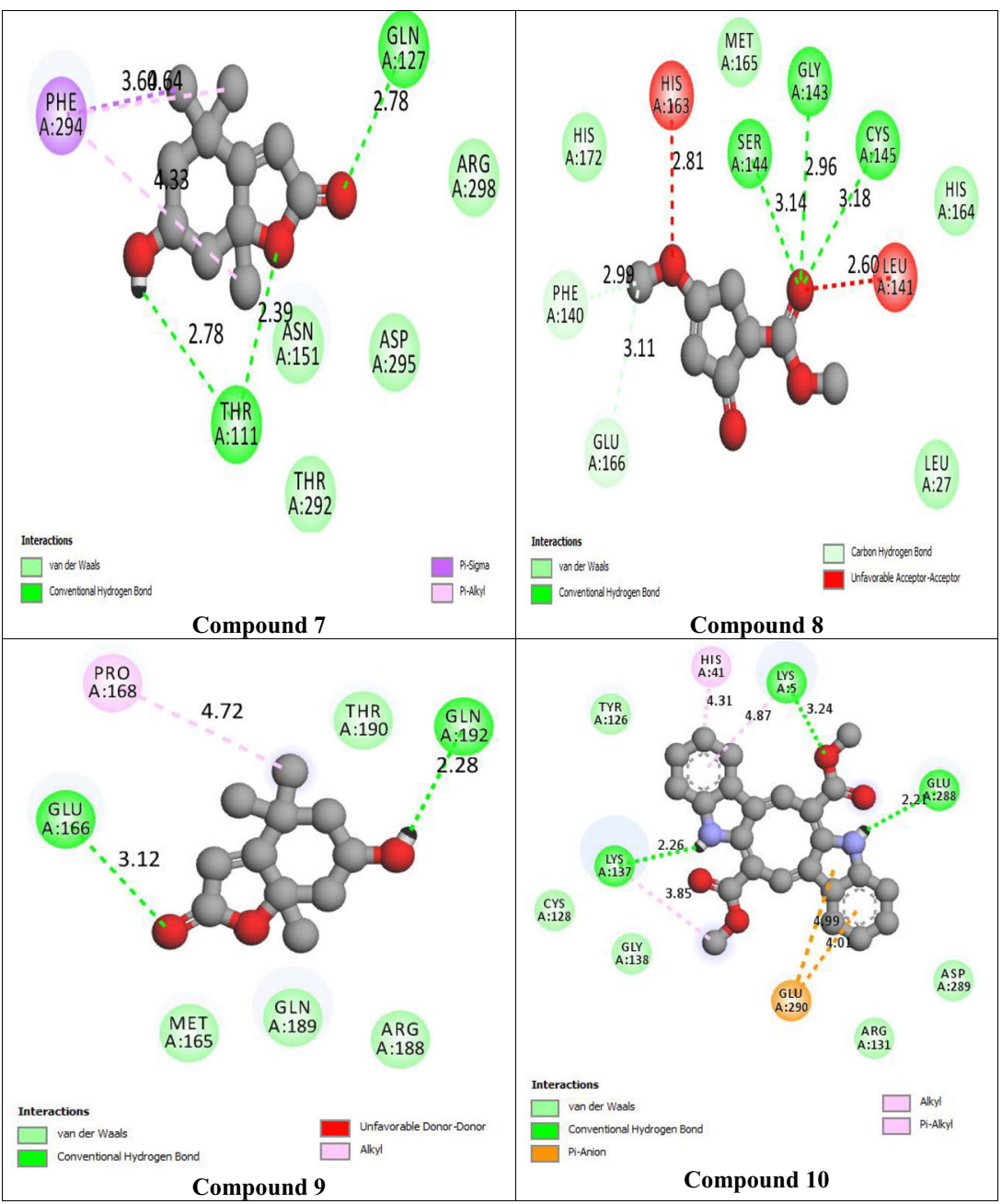


of all studied compounds. Also, re-docking of the co-crystal structure (2-acetamido-2-deoxy-beta-D-glucopyranose) as an inhibitor in the 1R42 with the abovementioned parameters and values in the "Materials and methods" section was done. Firstly, 2-acetamido-2-deoxy-beta-D-glucopyranose coordinates in the crystal complex of 1R42 were removed and the bond orders were checked. Then, we performed the docking studies of 2-acetamido-2-deoxy-beta-D-glucopyranose inside $1 \mathrm{R} 42$ to validate the docking protocol. Once the docking is done, select the best pose based on binding energy, ligandreceptor interactions, and the active site residues. Then, simply align both docked pose with that of co-crystallized structure, and then, RMSD was calculated lower than 1.1 $\AA$. Also, $2 \mathrm{D}$ interaction of the 2-acetamido-2-deoxy-beta-D-glucopyranose inhibitor inside 1R42 is summarized in Figure S2. As shown in Figure S2, we found that the 2-acetamido-2-deoxybeta-D-glucopyranose inhibitor interacts with GLN 189, ASP 615, UNK 908, UNK 907, and UNK 910 amino acid residues of 1R42 through hydrogen bond interactions which are in good agreement of those in the state of all studied compounds.

\section{Molecular docking}

Table 2 displays the binding energies obtained from molecular docking analysis results for all studied bioactive compounds and some proposed antiviral drugs against 6LU7, 6VYB, and 1R42. Figures 3 and 4 show the best docking poses of studied bioactive compounds $1-6$ and 7-10, respectively, inside 6LU7. Figures 5 and 6 show the best docking poses of studied bioactive compounds $1-6$ and 7-10, respectively, inside
Fig. 5 2D interaction of studied compounds (1-6) inside 6VYB

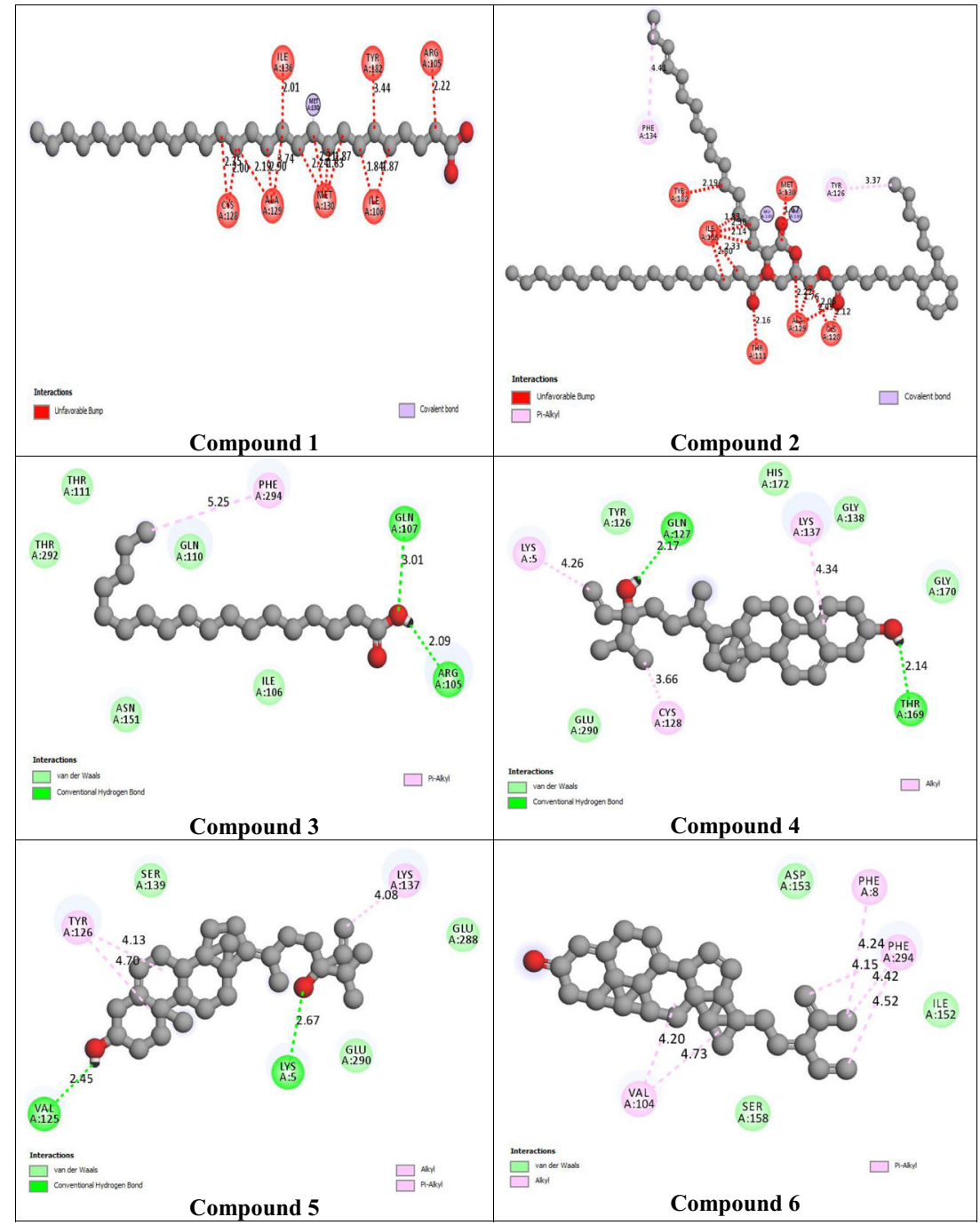


6VYB. Figure S3 shows the best docking poses of studied bioactive compounds $1-10$, inside $1 \mathrm{R} 42$. The number of $\mathrm{H}-$ bonds, $\mathrm{H}$-bonding residues, and $\mathrm{H}$-bonding distance produced from docking for all studied bioactive compounds against 1R42 is shown in Table 3. Chloroquine, hydroxychloroquine, azithromycin, simeprevir, baloxavir, lopinavir, and favipiravir also docked inside 6LU7, 6VYB, and 1R42 using the same protocol applied on all studied compounds. An in silico analysis study showed that only compound 10 can inhibit 6LU7, 6VYB, and 1R42 which has the higher binding energies against 6LU7, 6VYB, and 1R42 amino acid residues compared to chloroquine, hydroxychloroquine, azithromycin, simeprevir, baloxavir, lopinavir, and favipiravir inhibitors as shown in Tables 2 and 3. Compound 10 exhibits the highest binding energy $(-9.30 \mathrm{kcal} / \mathrm{mol})$ compared to other compounds and formed three hydrogen bond interactions with LYS 137, GLU 288, and LYS 5 of 6LU7 amino acid residues, alkyl interaction with catalytic dyad (HIS 41) of 6LU7, pialkyl interaction with LYS 5 of 6LU7, and van der Waals interactions with TYR 126, CYS 128, GLY 138, ASP 289, and ARG 131, as shown in Fig. 4. Also, compound 10 exhibits the highest binding energy $(-9.77 \mathrm{kcal} / \mathrm{mol})$ compared to other compounds and formed three hydrogen bond interactions with LYS 137, GLU 288, and LYS 5 of 6VYB amino acid residues, alkyl interaction with catalytic dyad (HIS 41) of 6VYB, pi-alkyl interaction with LYS 5 and LYS 137 of 6VYB, pi-anion interaction with GLU 290 of 6VYB, and van der Waals interactions with TYR 126, CYS 128, and ASP 289, as shown in Fig. 6. Finally, compound 10 exhibits the highest binding energy $(-9.97 \mathrm{kcal} / \mathrm{mol})$ compared to other compounds and formed three hydrogen bond interactions with UNK 907, UNK 910, and ASP 615 of 1R42 amino acid residues as shown in Table 3. From all the abovementioned, we can deduce that compound 10 shows the highest binding
Fig. 6 2D interaction of studied compounds (7-10) inside 6VYB

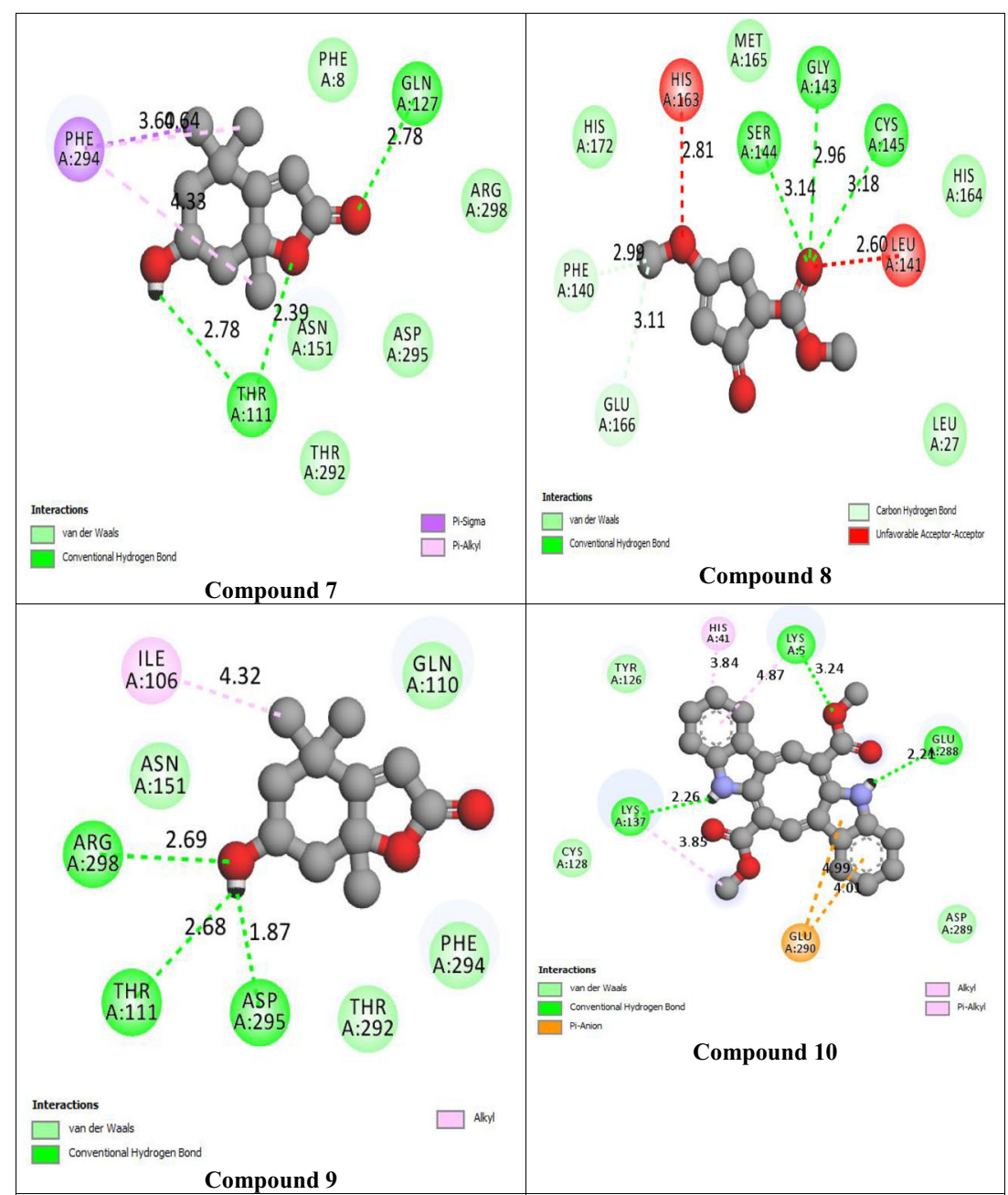


Table 3 Number of H-bonds, $\mathrm{H}$ bonding residues, and $\mathrm{H}$-bonding distance produced from docking for all studied bioactive compounds against $1 \mathrm{R} 42$
Table 4 Prediction of molecular property descriptors of all studied bioactive compounds

\begin{tabular}{|c|c|c|c|}
\hline Ligands & No. of H-bonds & H-bonding residues & H-bonding distance \\
\hline 1 & 2 & SER 47 & 2.43 \\
\hline 2 & 1 & MET 383 & 2.38 \\
\hline 3 & 1 & PHE 555 & 2.30 \\
\hline 4 & 1 & PRO 321 & 2.31 \\
\hline \multirow[t]{2}{*}{5} & \multirow[t]{2}{*}{2} & MET 383 & 2.33 \\
\hline & & UNK 907 & 2.39 \\
\hline 6 & 1 & ASP 615 & 2.27 \\
\hline \multirow[t]{2}{*}{7} & \multirow[t]{2}{*}{2} & ARG 559 & 2.21 \\
\hline & & UNK 908 & 2.25 \\
\hline \multirow[t]{2}{*}{8} & \multirow[t]{2}{*}{2} & PRO 321 & 2.18 \\
\hline & & SER 227 & 2.26 \\
\hline \multirow[t]{2}{*}{9} & \multirow[t]{2}{*}{2} & GLU 375 & 2.38 \\
\hline & & UNK 908 & 2.42 \\
\hline \multirow[t]{2}{*}{10} & \multirow[t]{2}{*}{2} & UNK 907, ASP 615 & 2.35 \\
\hline & & UNK 919 & 2.20 \\
\hline Chloroquine & 1 & PHE 555 & 2.40 \\
\hline Hydroxychloroquine & 1 & LEU 558 & 2.39 \\
\hline Azithromycin & 1 & UNK 910 & 2.37 \\
\hline \multirow[t]{2}{*}{ Simeprevir } & \multirow[t]{2}{*}{2} & ASN 51 & 2.32 \\
\hline & & ASP 615 & 2.44 \\
\hline Baloxavir & 1 & PRO 321 & 2.24 \\
\hline Lopinavir & 1 & MET 383 & 2.20 \\
\hline Favipiravir & 1 & SER 47 & 2.34 \\
\hline
\end{tabular}

\begin{tabular}{lllllll}
\hline Compounds & Mass & $\begin{array}{l}\text { Hydrogen } \\
\text { bond donor }\end{array}$ & $\begin{array}{l}\text { Hydrogen } \\
\text { bond acceptors }\end{array}$ & CLogP & $\begin{array}{l}\text { Molar } \\
\text { refractivity }\end{array}$ & TPSA \\
\hline 1 & 282.00 & 1 & 2 & 6.10 & 87.08 & 32.41 \\
2 & 428.00 & 2 & 2 & 7.11 & 135.68 & 150.55 \\
3 & 428.00 & 2 & 2 & 7.16 & 138.78 & 21.26 \\
4 & 368.00 & 0 & 1 & 0 & 0 & 35.49 \\
5 & 750.00 & 4 & 10 & 9.20 & 207.42 & 38.42 \\
6 & 186.00 & 1 & 5 & -0.60 & 41.68 & 46.00 \\
7 & 196.00 & 1 & 3 & -1.40 & 51.60 & 150.88 \\
8 & 256.00 & 1 & 2 & 5.55 & 77.94 & 36.19 \\
9 & 712.00 & 4 & 10 & 3.39 & 187.92 & 25.87 \\
10 & 398.00 & 2 & 4 & 3.94 & 114.13 & 36.76 \\
Chloroquine & 319.9 & 1 & 3 & 4.62 & 122.76 & 28.80 \\
Hydroxychloroquine & 335.9 & 2 & 4 & 3.64 & 125.54 & 48.61 \\
Azithromycin & 749.00 & 5 & 11 & 4.00 & 212.76 & 180.00 \\
Simeprevir & 749.92 & 2 & 10 & 4.80 & 178.98 & 194.00 \\
Baloxavir & 483.21 & 4 & 3 & 4.87 & 156.65 & 87.14 \\
Lopinavir & 628.80 & 4 & 5 & 5.90 & 189.76 & 120.65 \\
Favipiravir & 157.12 & 2 & 4 & -0.60 & 123.54 & 84.60 \\
\hline
\end{tabular}


energy compared to all studied compounds and all antiviral drugs against all studied receptors. So, compound 10 can act as an inhibitor for 6LU7, 6VYB, and 1R42.

\section{Analysis of drug likeness and ADMET properties of all studied bioactive compounds and antiviral drugs}

We can utilize Lipinski's rule of five in development and drug design applications to investigate the drug molecules' oral bioavailability based on five rules. So, we can measure the ability of all studied compounds to act as orally active drugs; the following rules must be justified (all studied compounds must have no more than one violation of the following standards to act as orally active drugs): (i) $\log P$ (octanol/water partition coefficient) calculating the molecule lipophilicity must be not larger than five. (ii) A molecular weight (MW) must be less than $500 \mathrm{Da}$. (iii) Hydrogen bond donors (nON) must be not more than five. (iv) Hydrogen bond acceptors (nOHN) must be not more than 10. The topological polar surface area (TPSA) must be not more than $160 \AA$; it calculates the drug molecule bioavailability and it links to the potential of the hydrogen bonding of the compound. The drug likeness of all studied compounds and antiviral drugs was computed and is summarized in Table 4. As shown in Table 4, all studied bioactive compounds followed Lipinski's rule of five and are expected to be orally active except compounds 5 and 9 . We can measure some features using the ADMET profile database such as blood-brain barrier (BBB) penetration, human intestinal absorption (HIA), Caco2 cell permeability, CYP inhibitory promiscuity, AMES toxicity, carcinogenicity, and rat acute toxicity LD50 which can help us to report the capability of the studied compounds to act as potential drug leads. All ADMET properties of all studied compounds and antiviral drugs are calculated and displayed in Table 5. As shown in Table 5, all studied compounds may cross the blood-brain barrier (BBB) and absorb in the human intestine (HIA) along the permeability for $\mathrm{Caco} 2$ cells, whereas compound 5 showed a negative result for BBB, HIA, and Caco 2 cell permeability. Also, all studied compounds were nontoxic and, according to the cytochrome P450 (CYP) values, indicate that all studied compounds are non-substrate and non-inhibitor of CYP enzymes [26, 37]. Carcinogenicity profile and rat acute toxicity LD50 values confirmed that all studied compounds are noncarcinogenic. Also, ADMET property and molecular property descriptors of all studied compounds are in good agreement with those of studied antiviral drugs as shown in Tables 4 and 5. From the previous studies in this section, we can confirm that most of the studied compounds can act as potential drug leads, except compound 5 .

\section{Combination therapy}

The global energy of interacted molecules was associated with free binding energy and their higher negative value explains

Table 5 Prediction of ADMET descriptors of all studied bioactive compounds

\begin{tabular}{|c|c|c|c|c|c|c|c|}
\hline Compounds & BBB & HIA & Caco2 permeability & CYP inhibitory promiscuity & AMES toxicity & Carcinogenicity & $\begin{array}{l}\text { Rat acute toxicity } \\
\mathrm{LD} 50, \mathrm{~mol} / \mathrm{kg}\end{array}$ \\
\hline 1 & $\mathrm{BBB}+$ & HIA+ & Caco2+ & Low & Nontoxic & Noncarcinogenic & 1.95 \\
\hline 2 & $\mathrm{BBB}+$ & HIA+ & $\mathrm{Caco} 2+$ & Low & Nontoxic & Noncarcinogenic & 2.29 \\
\hline 3 & $\mathrm{BBB}+$ & HIA+ & $\mathrm{Caco} 2+$ & Low & Nontoxic & Noncarcinogenic & 2.38 \\
\hline 4 & $\mathrm{BBB}+$ & HIA+ & $\mathrm{Caco} 2+$ & Low & Nontoxic & Noncarcinogenic & 2.60 \\
\hline 5 & BBB- & HIA- & Caco2 - & Low & Nontoxic & Noncarcinogenic & 2.17 \\
\hline 6 & $\mathrm{BBB}+$ & HIA+ & Caco2+ & Low & Nontoxic & Noncarcinogenic & 2.18 \\
\hline 7 & $\mathrm{BBB}+$ & HIA+ & Caco2+ & Low & Nontoxic & Noncarcinogenic & 2.21 \\
\hline 8 & $\mathrm{BBB}+$ & HIA+ & Caco2+ & Low & Nontoxic & Noncarcinogenic & 2.75 \\
\hline 9 & $\mathrm{BBB}+$ & HIA+ & $\mathrm{Caco} 2+$ & Low & Nontoxic & Noncarcinogenic & 2.70 \\
\hline 10 & $\mathrm{BBB}+$ & HIA+ & $\mathrm{Caco} 2+$ & Low & Nontoxic & Noncarcinogenic & 2.23 \\
\hline Chloroquine & $\mathrm{BBB}+$ & HIA+ & $\mathrm{Caco} 2+$ & Low & Nontoxic & Noncarcinogenic & 2.21 \\
\hline Hydroxychloroquine & $\mathrm{BBB}+$ & HIA+ & $\mathrm{Caco} 2+$ & Low & Nontoxic & Noncarcinogenic & 2.15 \\
\hline Azithromycin & $\mathrm{BBB}+$ & HIA+ & $\mathrm{Caco} 2+$ & Low & Nontoxic & Noncarcinogenic & 2.23 \\
\hline Simeprevir & $\mathrm{BBB}+$ & HIA+ & Caco2+ & Low & Nontoxic & Noncarcinogenic & 2.29 \\
\hline Baloxavir & $\mathrm{BBB}+$ & HIA+ & Caco2+ & Low & Nontoxic & Noncarcinogenic & 2.34 \\
\hline Lopinavir & $\mathrm{BBB}+$ & HIA+ & $\mathrm{Caco} 2+$ & Low & Nontoxic & Noncarcinogenic & 2.70 \\
\hline
\end{tabular}


higher binding probability. Based on the molecular docking study, it was noticed that the predicted antiviral activity of caulerpin (compound 10) against SARS-CoV-2 3-chymotrypsin-like protease, SARS-CoV-2 spike protein, and a host target human angiotensin-converting enzyme 2 (ACE2) receptors is larger than those of all drugs in this study. In this section, we study the combination therapy of compounds yielding the highest binding in molecular docking (caulerpin) along with the highest binding energy in antiviral drugs lopinavir and simeprevir for disrupting the stability of SARS-CoV-2 3-chymotrypsin-like protease, SARS-CoV-2 spike protein, and a host target human angiotensinconverting enzyme 2 (ACE2) receptors. As shown in Table 1, caulerpin showed inhibition activity against different diseases; also in the ADMET section, this compound is safe and nontoxic for biological applications. So, we can use it in combination therapy along with drugs such as lopinavir and simeprevir drugs which are actually used in the treatment of COVID-19 patients. The obtained binding energy of compound 10 against all studied receptors is higher than those of lopinavir, simeprevir, hydroxychloroquine, chloroquine, and amprenavir drugs. These results of molecular docking indicated that compound $\mathbf{1 0}$ as an adjunct drug could be a potent antiviral molecule along with lopinavir and simeprevir, or other antiviral conventional drugs, for the disruption of the integrity of SARS-CoV2 protein receptors. Lopinavir and simeprevir drugs produce the highest binding energy toward 6LU7, 6VYB, and 1R42 compared to the other drugs. Figures 7, 8, and 9 show the schematic presentation for a combination by simeprevir with compound 10 and tricombination therapy by simeprevir + lopinavir with compound 10 suppressing the activity of 6LU7, 6VYB, and 1 R42 which play essential role in the completion of SARS-CoV-2 life cycle respectively. From these figures, simeprevir,
Fig. 7 The schematic presentation for (8a) a combination therapy by simeprevir with caulerpin and (8b) a tricombination therapy by simeprevir and lopinavir with caulerpin activity of 6LU7 essential role in completion of SARSCoV2 life cycle

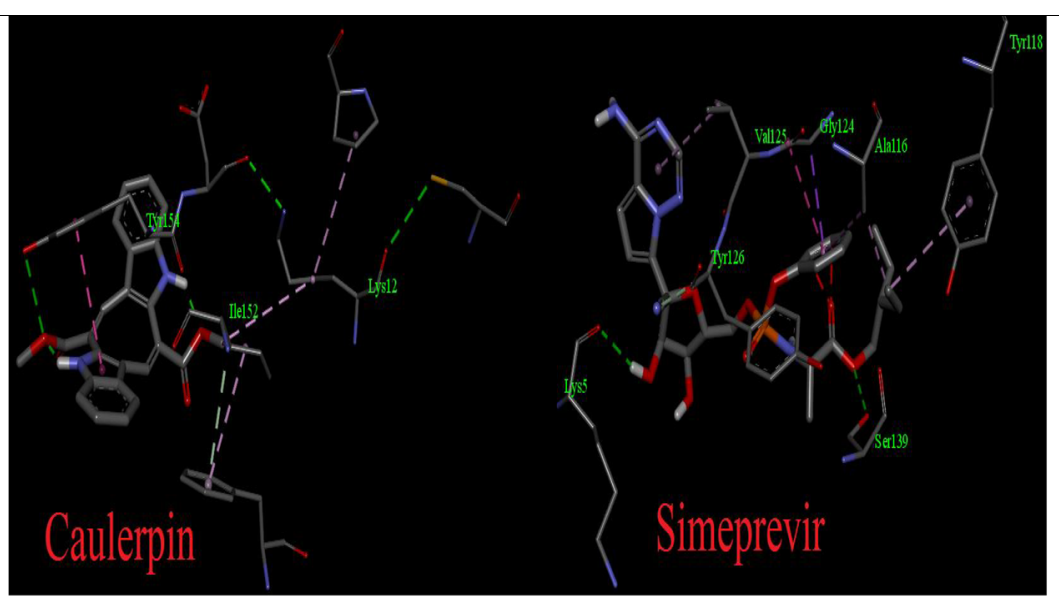

(8a)

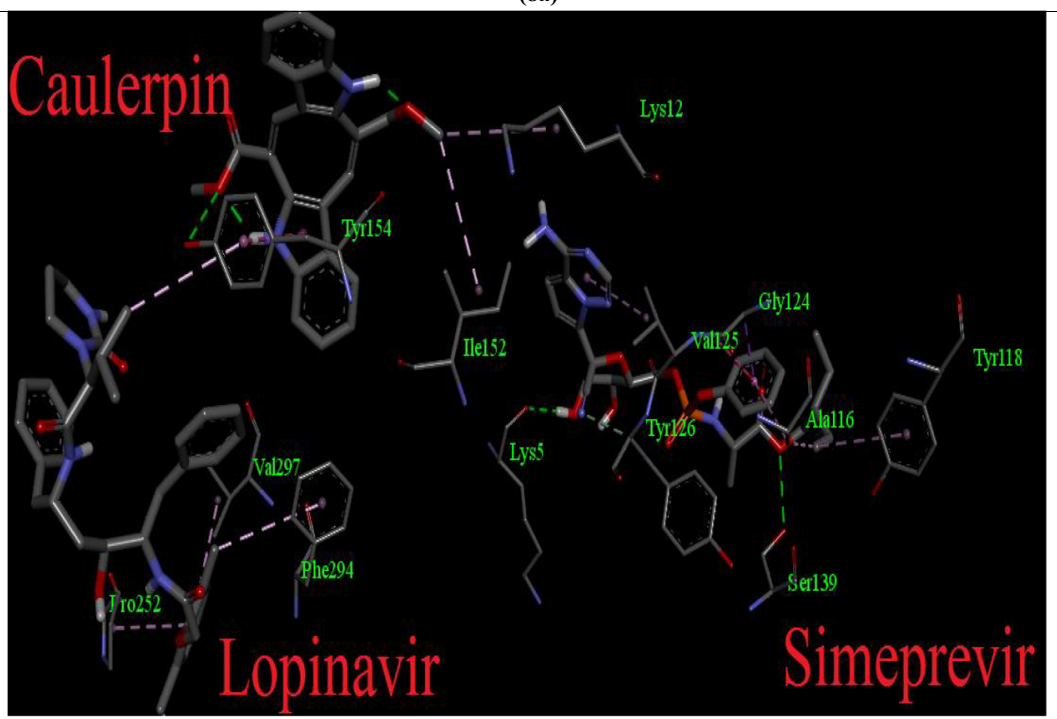

(8b) 
lopinavir, and compound $\mathbf{1 0}$ when docked inside all studied receptors interact with different amino acid residues in combination and tricombination therapy. Hence, the combination of compound $\mathbf{1 0}$ with simeprevir and lopinavir is highly effective against SARS-CoV-2 proteases, and these drugs can be explored further for drug repurposing against the successful inhibition of COVID-19. Finally, the antiviral activity of lopinavir, simeprevir, hydroxychloroquine, chloroquine, and amprenavir could be increased against SARS-CoV-2 by using caulerpin as combination therapy.

\section{Conclusion}

This study has emphasized in knowing the exact reason by considering the four receptor proteins of SARS-CoV-2: SARS-
CoV-2 main protease (PDB ID: 6LU7), SARS-CoV main protease (PDB ID: 3TNT), SARS-CoV-2 spike protein domain (PDB ID: 6VYB), and host target human angiotensinconverting enzyme 2 (ACE2) receptor why FDA (Food and Drug Administration)-approved drugs or other conventional drugs are not working against SARS-CoV-2. The protein disordered results from ANCHOR showed that all studied receptors in this study are highly stable proteins, so it is quite difficult to unstable the integrity of these proteins by using individual drugs. The molecular docking analysis revealed that bioactive compound 10 (caulerpin) has the highest binding affinity against all studied receptors compared to other studied compounds and some antiviral drugs. The ADMET properties strongly provide the ability of most of all studied compounds to act as a drug, except compound 5. Molecular property descriptors confirmed that most of all studied compounds did not violate any of
Fig. 8 The schematic presentation for (10a) a combination therapy by simeprevir with caulerpin and (10b) a tricombination therapy by simeprevir and lopinavir with caulerpin activity of SARS-CoV2 spike protein (6VYB)

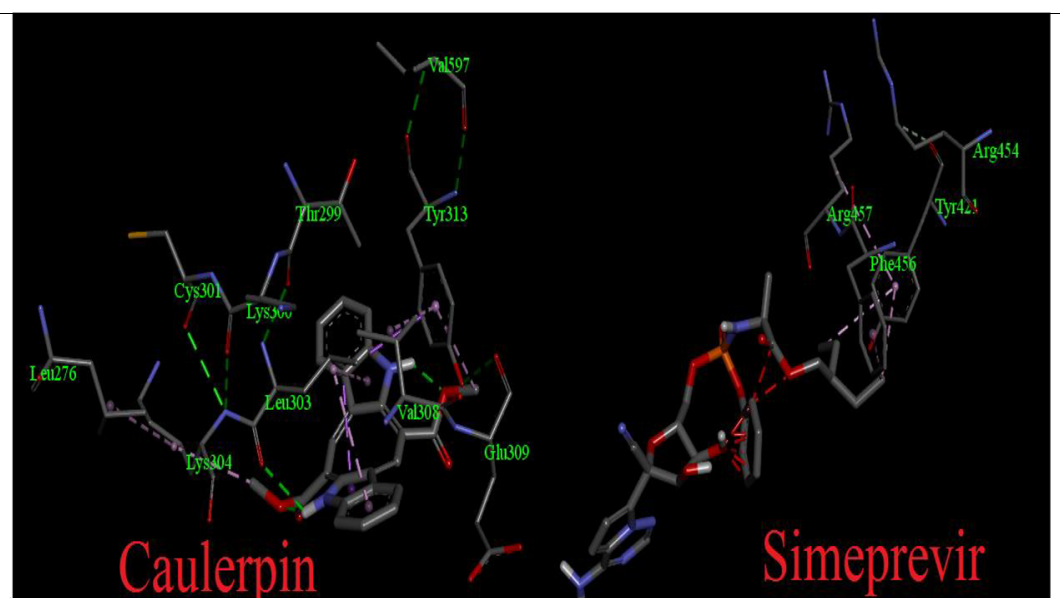

(10a)

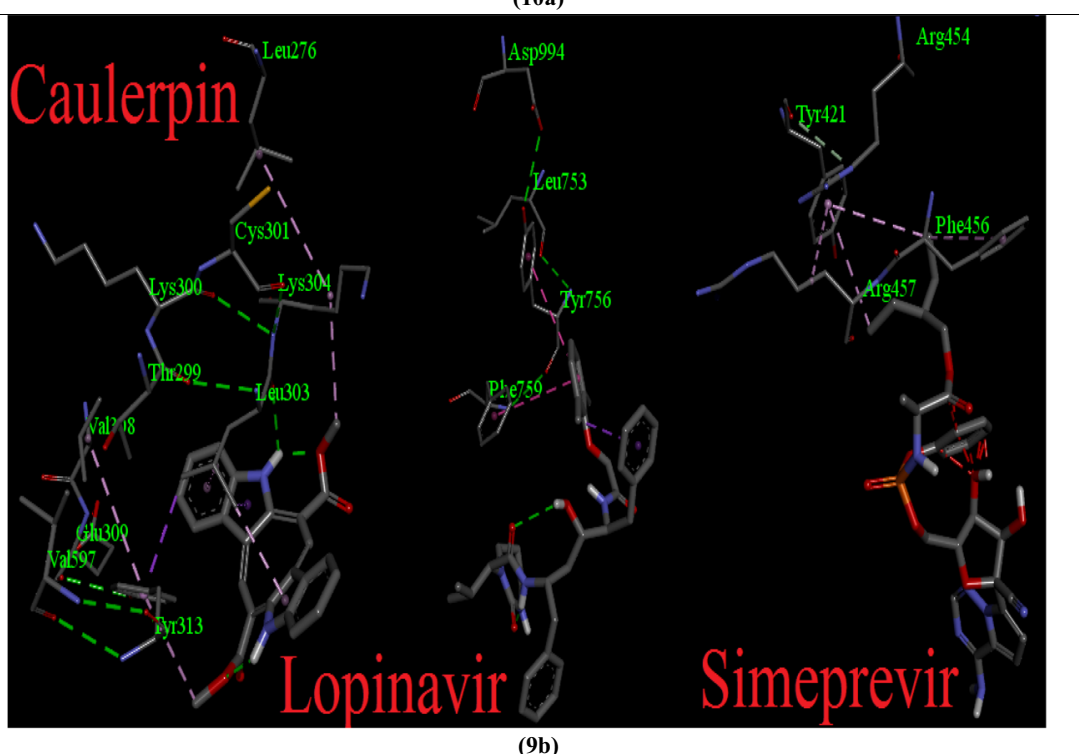


Fig. 9 The schematic presentation for (11a) a combination therapy by simeprevir with caulerpin and (11b) a tricombination therapy by simeprevir and lopinavir with caulerpin activity and a host target human angiotensin-converting enzyme 2 (ACE2) receptor (1R42)

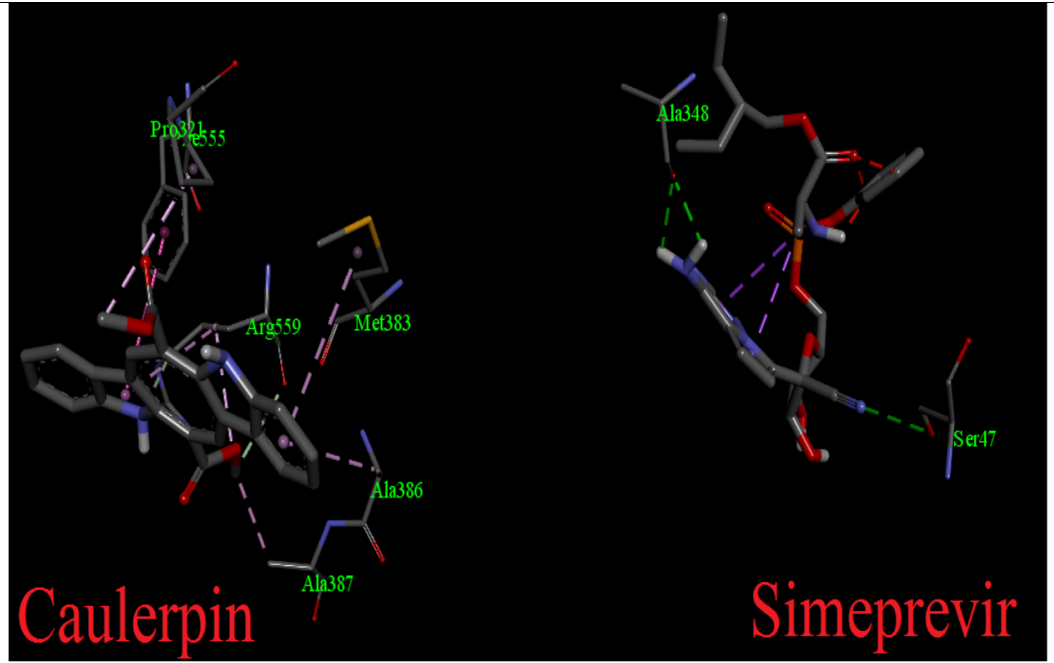

(11a)

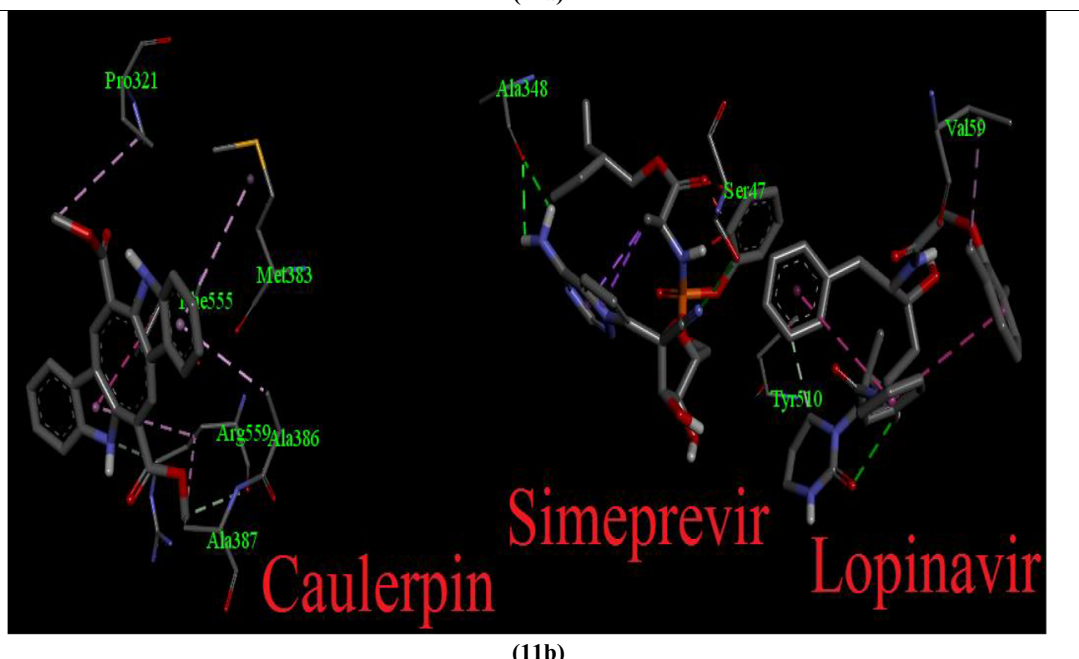

(11b)
Lipinski's rule of five and exhibit significant biological activities. Based on protein disordered results, we study the combination and tricombination therapy for compounds along with simeprevir in combination and along simeprevir + lopinavir, for disrupting the stability of SARS-CoV-2 proteases. Hence, the combination of compound 10 with simeprevir and lopinavir is highly effective against SARS-CoV-2 proteases, and these drugs can be explored further for drug repurposing against the successful inhibition of COVID-19. Finally, the antiviral activity of lopinavir, simeprevir, hydroxychloroquine, chloroquine, and amprenavir could be increased against SARS-CoV-2 by using caulerpin as combination therapy.

Supplementary Information The online version contains supplementary material available at https://doi.org/10.1007/s11224-020-01723-5.

Authors' contributions All authors contributed to the study conception and design. Material preparation and data collection were performed by H. R. Abd El-Mageed, Doaa A. Abdelrheem, Shimaa A. Ahmed, Aziz A. Rahman, Khaled N. M. Elsayed, Sayed A. Ahmed, Ashraf A. ELBassuony, and Hussein S. Mohamed. Data analysis was performed by
H. R. Abd El-Mageed. The first draft of the manuscript was written by H. R. Abd El-Mageed and all authors commented on previous versions of the manuscript. All authors read and approved the final manuscript.

Data availability All data generated or analyzed during this study are included in the article and supplementary materials.

\section{Compliance with ethical standards}

Conflict of interest The authors declare that they have no conflict of interest.

Consent to participate Not applicable.

Consent for publication Not applicable.

\section{References}

1. Li, Y.; Zhang, J.; Wang, N.; Li, H.; Shi, Y.; Guo, G.; Zou, Q. Therapeutic drugs targeting $2019-\mathrm{nCoV}$ main protease by highthroughput screening. bioRxiv. 2020 
2. Zhu N, Zhang D, Wang W, Li X, Yang B, Song J, Niu P (2020) A novel coronavirus from patients with pneumonia in China, 2019. N Engl J Med 382:727-733

3. Xu X, Chen P, Wang J, Feng J, Zhou H, Li X, Hao P (2020) Evolution of the novel coronavirus from the ongoing Wuhan outbreak and modeling of its spike protein for risk of human transmission. Sci China Life Sci 63:457-460

4. Xia B, Kang X (2011) Activation and maturation of SARS-CoV main protease. Protein Cell 2:282-290

5. Lu IL, Mahindroo N, Liang PH, Peng YH, Kuo CJ, Tsai KC, Wu SY (2006) Structure-based drug design and structural biology study of novel nonpeptide inhibitors of severe acute respiratory syndrome coronavirus main protease. J Med Chem 49:5154-5161

6. Zhang, H.; Saravanan, K. M.; Yang, Y.; Hossain, M. T.; Li, J.; Ren, $\mathrm{X}$.; Wei, Y. Deep learning based drug screening for novel coronavirus 2019-nCov. Preprints. 2020

7. Baell JB (2016) Feeling nature's PAINS: natural products, natural product drugs, and pan assay interference compounds (PAINS). J Nat Prod 79:616-628

8. ÖZȘEN, Ö.; KIRAN, İ.; ALI, Ö.; DAĞ, İ. Antimicrobial evaluation of oleic acid biotransformation metabolites. International Congress on Applied Biological Sciences 2015

9. Mericli F, Becer E, Kabaday H, Hanoglu A, Yigit Hanoglu D, Ozkum Yavuz D, Vatansever S (2017) Fatty acid composition and anticancer activity in colon carcinoma cell lines of Prunus dulcis seed oil. Pharm Biol 55:1239-1248

10. Sands JA (1977) Inactivation and inhibition of replication of the enveloped bacteriophage $\varphi 6$ by fatty acids. Antimicrob Agents Chemother 12:523-528

11. Hoet S, Pieters L, Muccioli GG, Habib-Jiwan JL, Opperdoes FR, Quetin-Leclercq J (2007) Antitrypanosomal activity of triterpenoids and sterols from the leaves of Strychnos spinosa and related compounds. J Nat Prod 70:1360-1363

12. Lee JA, Cho Y, Hong SS, Ahn E (2017) Anti-obesity activity of saringosterol isolated from Sargassum muticum (Yendo) Fensholt extract in 3T3-L1 cells. Phyther Res 31:1694-1701

13. Chen Z, Liu J, Fu Z, Ye C, Zhang R, Song Y, Liu H (2014) 24 (S)Saringosterol from edible marine seaweed Sargassum fusiforme is a novel selective LXR $\beta$ agonist. J Agric Food Chem 62:6130-6137

14. Ahmed, S. A.; Rahman, A. A.; Elsayed, K. N.; Abd El-Mageed, H. R.; Mohamed, H. S.; Ahmed, S. A. Cytotoxic activity, molecular docking, pharmacokinetic properties and quantum mechanics calculations of the brown macroalga Cystoseira trinodis compounds. J Biomol Struct Dyn 2020, 1-31

15. Ododo MM, Choudhury MK, Dekebo AH (2016) Structure elucidation of $\beta$-sitosterol with antibacterial activity from the root bark of Malva parviflora. Springerplus. 5:1210

16. Parvez MK, Alam P, Arbab AH, Al-Dosari MS, Alhowiriny TA, Alqasoumi SI (2018) Analysis of antioxidative and antiviral biomarkers $\beta$-amyrin, $\beta$-sitosterol, lupeol, ursolic acid in Guiera senegalensis leaves extract by validated HPTLC methods. Saudi Pharm J 26:685-693

17. Shahat AA, Hidayathulla S, Khan AA, Alanazi AM, Al Meanazel OT, Alqahtani AS, Hussein AA (2019) Phytochemical profiling, antioxidant and anticancer activities of Gastrocotyle hispida growing in Saudi Arabia. Acta Trop 191:243-247

18. Shiota A, Hada T, Baba T, Sato M, Yamanaka-Okumura H, Yamamoto H, Takeda E (2010) Protective effects of glycoglycerolipids extracted from spinach on 5-fluorouracil induced intestinal mucosal injury. J Med Investig 57:314-320
19. Zhang J, Li C, Yu G, Guan H (2014) Total synthesis and structureactivity relationship of glycoglycerolipids from marine organisms. Mar Drugs 12:3634-3659

20. Baidya M, Griffin KA, Yamamoto H (2012) Catalytic enantioselective O-nitrosocarbonyl aldol reaction of $\beta$-dicarbonyl compounds. J Am Chem Soc 134:18566-18569

21. Yang X, Kang MC, Lee KW, Kang SM, Lee WW, Jeon YJ (2011) Antioxidant activity and cell protective effect of loliolide isolated from Sargassum ringgoldianum subsp. coreanum. Algae 26:201208

22. Grabarczyk M, Wińska K, Mączka W, Potaniec B, Anioł M (2015) Loliolide-the most ubiquitous lactone. Folia Biol Oecologica 11:18

23. Abubakar M, Majinda R (2016) GC-MS analysis and preliminary antimicrobial activity of Albizia adianthifolia (Schumach) and Pterocarpus angolensis (DC). Medicines. 3:3

24. Librán-Pérez M, Pereiro P, Figueras A, Novoa B (2019) Antiviral activity of palmitic acid via autophagic flux inhibition in zebrafish (Danio rerio). Fish Shellfish Immunol 95:595-605

25. Lunagariya J, Bhadja P, Zhong S, Vekariya R, Xu S (2019) Marine natural product bis-indole alkaloid caulerpin: chemistry and biology. Mini Rev Med Chem 19:751-761

26. Abdelrheem DA, Abd El-Mageed HR, Mohamed HS, Rahman AA, Elsayed KN, Ahmed SA (2020) Bis-indole alkaloid caulerpin from a new source Sargassum platycarpum: isolation, characterization, in vitro anticancer activity, binding with nucleobases by DFT calculations and MD simulation. J Biomol Struct Dyn:1-11. https:// doi.org/10.1080/07391102.2020.1784285

27. Sang, P.; Tian, S. H.; Meng, Z. H.; Yang, L. Q. Insight derived from molecular docking and molecular dynamics simulations into the binding interactions between HIV-1 protease inhibitors and SARS-CoV-2 3CLpro. Preprint. 2020

28. Raghavendra S, Rao Aditya SJ, Kumar V, Ramesh CK Multiple ligand simultaneous docking (MLSD): a novel approach to study the effect of inhibitors on substrate binding to PPO. Computational Biology and Chemistry. https://doi.org/10.1016/j.compbiolchem. 2015.09.008

29. Lipinski CA (2004) Lead- and drug-like compounds: the rule-offive revolution. Drug Discov Today Technol 1:337-341

30. Cheng F, Li W, Zhou Y, Shen J, Wu Z, Liu G (2012) admetSAR: a comprehensive source and free tool for assessment of chemical ADMET properties. J. Chem. Inf. Model 52:3099-3105. https:// doi.org/10.1021/ci300367a

31. Mészáros B, Erdős G, Dosztányi Z (2018) IUPred2A: contextdependent prediction of protein disorder as a function of redox state and protein binding. Nucleic Acids Res 2:329-337. https://doi.org/ 10.1093/nar/gky384

32. Dosztányi Z (2018) Prediction of protein disorder based on IUPred. Protein Sci. https://doi.org/10.1002/pro.3334

33. Thomas PD, Dill KA (1996) An iterative method for extracting energy-like quantities from protein structures. Proceedings of the National Academy of Sciences 93:11628-11633. https://doi.org/ 10.1073/pnas.93.21.11628

34. Dosztanyi Z, Csizmok V, Tompa P, Simon I (2005) The pairwise energy content estimated from amino acid composition discriminates between folded and intrinsically unstructured proteins. $\mathrm{J}$ Mol Biol 347:827-839. https://doi.org/10.1016/j.jmb.2005.01.071

35. Mészáros B, Simon I, Dosztányi Z (2009) Prediction of protein binding regions in disordered proteins. PLoS Comput Biol 5(5). https://doi.org/10.1371/journal.pcbi.1000376

36. Ahmed SA, Abdelrheem DA, El-Mageed HRA et al (2020) Destabilizing the structural integrity of COVID-19 by caulerpin 
and its derivatives along with some antiviral drugs: an in silico approaches for a combination therapy. Struct Chem. https://doi. org/10.1007/s11224-020-01586-w

37. Wang, J. Fast identification of possible drug treatment of coronavirus disease -19 (COVID-19) through computational drug repurposing study. J. Chem. Inf. Mod. 2020
Publisher's note Springer Nature remains neutral with regard to jurisdictional claims in published maps and institutional affiliations. 